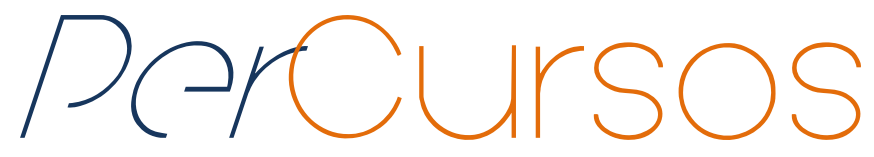

\title{
Resenha do livro “L’image partagée: La photographie numérique"
}

GUNTHERT, André. L'image partagée: La photographie numérique. Paris : Éditions Textuel, 2015. $176 \mathrm{p}$.

\section{Daniela Queiroz Campos}

Pós-doutoranda EHESS - Paris. Bolsista CNPq.

Brasil

camposdanielaqueiroz@gmail.com

\section{Para citar esta resenha:}

CAMPOS, Daniela Queiroz. Resenha do livro L'image partagée: La photographie numérique. Revista PerCursos. Florianópolis, v. 17, n. 33, p. 176 -182, jan./abr. 2016.

\section{DOI: 10.5965/1984724617332016176}

http://dx.doi.org/10.5965/1984724617332016176 
Em seu mais recente livro L'image partagée, o mestre de conferência da École des Hautes Études en Sciences Sociales (EHESS) de Paris problematiza a fotografia numérica na contemporaneidade. André Gunthert é membro do Centre d'Histoire et de Théorie des Arts (CEHTA) e ministra seminários acerca da História Visual, enfocando principalmente os usos ordinários das imagens e a cultura visual. O autor dedica-se aos estudos da fotografia desde sua tese doutoral (GUNTHERT, 1999), orientada por um dos mais expressivos historiadores da arte francesa do século XX, Louis Marins.

Para André Gunthert, vivemos em um momento de aceleração, o que ele considera um belo presente para um historiador. O autor faz a clássica e corrente pergunta: pode o historiador dedicar-se a observar o presente? Contudo, não a responde utilizando a historiografia francesa do tempo presente (RÉMOND, 2003). Retoma o clássico texto de Marc Bloch (2002) e sublinha a história não somente como ciência do passado, mas enfoca a atividade historiográfica como o estudo das mudanças. É justamente esta história em construção que possibilita ao historiador escrever sobre o que ele assiste, neste caso específico, a “[...] rápida evolução das práticas visuais” (GUNTHERT, 2015, p. 7).

As práticas visuais contemporâneas assinalam a fotografia numérica não como uma revolução, mas uma evolução das práticas da fotografia. A fotografia passou por uma transição numérica nos últimos 15 anos. Desde o aparecimento dos primeiros compactos numéricos, até a atualidade, muito se modificou. Para além do registro imagético, André Gunthert ateve-se a uma amplitude de mudanças históricas, comportamentais, sociais, culturais. O historiador analisa o novo como o resultado de um esforço de qualificação simbólica, uma maneira de qualificar um fenômeno, do mesmo modo como fora feito para construir uma oposição entre a Idade Média e a Renascença.

Assim como o fim da História (ANDERSON, 1992), ou o fim da História da Arte (BELTING, 2012), o fim da fotografia também já fora proclamado, este último na década de 1990, por Ritchin (1990) e Mitchell (1992). O elemento crucial era o retoque, que ameaçava um regime de verdade - principalmente com a primeira versão do software Photoshop, difundido pela Adobe em 1990. 
Na obra, André Gunthert analisa os usos e as modificações da fotografia numérica no decorrer do século XXI. Contudo, como é característico de seu trabalho, também dedicou-se à problematização histórica da mesma. Os primeiros dados numéricos visuais vieram de Marte, referem-se a dados da NASA. No ano de 1965, a agência norteamericana efetuou a numerização de dados imagéticos em virtude da enorme distância que as informações precisavam percorrer - do satélite Mariner4 até a Terra. No filme De volta ao futuro, de 1985, o ator Michel J. Fox (encenando o personagem Marty McFly) apresentava-se portando uma câmera JVC GR-C1, que permitia a filmagem diretamente em cassete - tratava-se do fotocaptor CCD, que equiparou às primeiras câmeras numéricas a partir do início da década de 1990. Esses dois exemplos são testemunhos de antecedentes da fotografia numérica.

Gunthert faz aporte aos escritos de Mitchell (1992), para quem a fotografia numérica inaugura a pós-fotografia. Mesmo visivelmente idênticas, para o pesquisador australiano, elas contêm diferenças profundas - apresentando naturezas díspares. A fotografia numérica inauguraria, assim, uma época de suspeita da veracidade das imagens - acreditava-se na ruína do traço indicial.

A imagem numérica, a partir dos anos 1990, modifica consideravelmente o mundo da imprensa e da edição. Adentram aquele mundo os softwares de tratamentos de imagem, o scanner, os sites e os portais. O métier dos jornalistas modifica-se sobremaneira, mas não provoca mudança perceptível ao leitor. Quanto à fotografia numérica, oferece principalmente a possibilidade do retoque ao grande público, ela passa a receber ampla problematização. O retoque, anteriormente efetuado e conhecido pelos profissionais, invade também a fotografia amadora. Essa quase "popularização" pode ser apontada como um dos fatores que mais causou discussões acerca da fotografia na atualidade. "Ao consultar as obras de referência do século passado, os estudantes dos anos 2010 ficaram surpresos ao constatar que Roland Barthes não mais que Susan Sontag ou Rosalind Krauss não se preocuparam com a questão do retoque" (GUNTHERT, 2015, p. 75), o que o historiador francês considera uma miopia resultante de uma hipocrisia do mundo profissional de longa data. Depois do Photoshop, o uso do retoque é ampliado, e mais importante do que isso, ganha visibilidade. 
As câmeras de fotografia numérica apresentaram crescimento considerável entre os anos de 2002-2004. Os fabricantes conservaram a morfologia das antigas câmeras, o que não gerou estranhamento da clientela. No entanto, estas novas câmeras possibilitavam a verificação imediata da imagem - através da tela acoplada ao equipamento.

Inúmeros exemplos de publicação midiática de fotografias numéricas foram colocados no livro. Entre elas, as fotografias de Abou Ghraib que, em 2004, expuseram as imagens de tortura de prisioneiros iraquianos por guardas norte-americanos. Estas fotografias numéricas realizadas pelos próprios guardas, com maquinário destinado ao grande público, foram vinculadas a jornais e imediatamente consideradas verídicas.

Para Gunthert, foram duas as grandes transformações da fotografia numérica: a câmera fotográfica acoplada ao aparelho celular e o acesso desses telefones portáteis à internet. A junção de câmeras fotográficas aos celulares transforma "todos em produtores de imagens". O atentado de 7 de julho de 2005, na cidade de Londres, foi objeto de forte cobertura midiática. Na ocasião, a impossibilidade da chegada de jornalistas ao local propiciou a publicação de um sem-número de imagens numéricas, feitas por amadores a partir de seus telefones portáteis, quase que imediatamente após o ataque.

A fotografia conectada modificou o cenário cultural de uma maneira inesperada. Celulares conectados à internet começaram a ser comercializados pela marca de computadores Apple no ano de 2008. A venda desse tipo de telefone rapidamente ultrapassou a das câmeras. No ano de 2011, a França registou a venda de 12 milhões de smartphones, contra 4,6 milhões de aparelhos fotográficos. O smartphone transforma-se em aparelho universal de fotografia. As câmeras fotográficas ficam cada vez mais restritas à experiência do turismo e do exótico. Em contrapartida, a capacidade de registro por meio dos smartphones "[...] transforma cada um de nós em turistas do cotidiano" (GUNTHERT, 2015, p. 137). Estas imagens têm transferência imediata, seja por mensagens instantâneas ou por redes sociais. O Facebook, aberto ao público no ano de 
2006, facilita consideravelmente a fluidez da imagem. Em 2013, coleção de fotografias mais importante do planeta passou a ser dele - somam-se mais de 250 bilhões.

Para o historiador, o choque da numeralização imagética corresponde à mais significativa mutação tecnológica fotográfica desde a invenção do negativo. A fluidez numérica corresponderia a um novo degrau, que segue ao da difusão da imagem após a reprodutibilidade fotográfica, como analisada por Walter Benjamin (2010a). No artigo Archéologie de la « Petit histoire de la photographie » (Gunthert, 2015), o autor pontua Benjamin - especialmente em função do artigo publicado na revista cultural alemã Die Literarische Welt (BENJAMIN 2010b) no ano de 1925 - como um dos primeiros intelectuais de envergadura a trabalhar a questão da fotografia com seriedade.

A desmaterialização do suporte ocasiona quatro grandes consequências: a modificação radical da condição de arquivagem; a preservação da possibilidade de alteração após o ato fotográfico; a facilidade da telecomunicação imediata e por fim; uma universalidade em razão da integração dos conteúdos difundidos pela internet. Acerca das várias críticas recebidas por essa nova forma fotográfica, Gunthert (2015) afirma que a resistência à inovação é o sintoma mais regular num processo de transição cultural e que a própria fotografia já passou por outros processos de modificação, tendo ela sempre se adaptado a eles.

O acesso a dados de imagens também se transforma significativamente nesta “nova” etapa do registro imagético. É notório o aumento na utilização de plataformas de imagens, como Flickr de 2004, O Youtube, criado em 2005. Estas plataformas disponibilizam gratuitamente a visualização em boa qualidade e de forma simples de conteúdos fotográficos e videográficos.

A desespecialização da fotografia altera essencialmente o paradigma fotográfico. Este novo uso da fotografia fora comparado ao processo de miniaturização do relógio. Processo que afeta a relojoaria entre os séculos XVI e XIX e transforma o relógio não mais em um mecanismo público monumental (DAVID, 1987). A fotografia tem chance de desaparecer? Segundo Gunthert (2015), ao contrário, a ela adicionou-se universalidade e 
apropriabilidade, projetando-a para além da promessa de democratização da produção visual.

O livro dedica-se, em suas últimas páginas, à prática fotográfica mais representativa da atualidade: o selfie. Uma das práticas mais antigas da imagem conectada, trata-se de uma auto-fotografia contextual. Como inovação técnica, a autofotografia instantânea fora desenvolvida pela Polaroid, contudo sua versão numérica fora denominada selfie. Apesar de visível desde 2000, o nome passa a ser amplamente difundido a partir de 2013, com uma série de artigos publicados pela mídia periódica norte-americana.

André Gunthert apresenta-nos, em um texto leve, a análise que parte da história da arte e problematiza imagens ordinárias. Como Ihe é característico, trata imagens atuais e contemporâneas e faz interessante e profunda análise de seu objeto. Seu livro oferecenos excelente exemplo da problematização que um historiador pode fazer de seu próprio tempo, mais do que isso, mostra-nos que a sagacidade está nos olhos de quem vê e de quem escreve - não existe imagem rasa, existem aqueles que se enganam com sua fluidez.

\section{Referências}

ANDERSON, Perry. O fim da história: de Hegel a Fukuyama. Rio de Janeiro: Jorge Zahar Editor, 1992.

BELTING, Hans. O fim da história da arte. São Paulo: Cosac Naify, 2012.

BENJAMIN, Walter. A obre de arte na era de sua reprodutibilidade técnica. In: BENJAMIN, Walter. Obras escolhidas vol.1: magia e técnica, arte e política: ensaio sobre literatura da história cultura. São Paulo: Brasiliense, 2010a.

BENJAMIN, Walter. Pequena história da fotografia. In: BENJAMIN, Walter.. Obras escolhidas vol.1: magia e técnica, arte e política: ensaio sobre literatura da história cultura. São Paulo: Brasiliense, 2010b.

BLOCH, Marc. Apologia da história ou o ofício do historiador. Rio de Janeiro: Jorge Zahar Editor, 2002. 
DAVID, Landes S. A revolução do tempo: os relógios e o nascimento do mundo moderno. Lisboa: Editora Gradiva, 2009.

GUNTHERT, André. La conquête de l'instantané : archéologie de l'imaginaire photographique en France (1841-1895). 1999, oo f. Tese (Doutorado em História) - École des Hautes Études en Sciences Sociales, Paris, 1999.

GUNTHERT, André. Archéologie de la « Petit histoire de la photographie ». In: CARERI, Giovanni et DIDI-HUBERMAN, Georges. L'histoire de l'art depuis Walter Benjamin. Paris: Éditions Mimésis, 2015.

MITCHELL, William John. The reconfigured eye: visual truth in the post-photographic era. Cambridge: MIT Press, 1992.

RÉMOND, René. Uma história presente. In: RÉMOND, René (Org.). Por uma história política. Rio de Janeiro: Editora Fundação Getúlio Vargas: 2003.

RITCHIN, Fred. In our own image: the coming revolution in photography. New York: Aperture, 1990.

Recebida em: 08/03/2016 Aprovada em: 09/03/2016

Universidade do Estado de Santa Catarina - UDESC Centro de Ciências Humanas e da Educação - FAED

Revista PerCursos Volume 17 - Número 33 - Ano 2016 revistapercursos@gmail.com 